\title{
Continuous Infusion of Flumazenil in the Management of Benzodiazepines Detoxification
}

\author{
Anna Benini ${ }^{1}$, Rossella Gottardo ${ }^{2}$, Cristiano Chiamulera ${ }^{1}$, Anna Bertoldi ${ }^{3}$, \\ Lorenzo Zamboni $^{3 *}$ and Fabio Lugoboni ${ }^{3}$ \\ ${ }^{1}$ Department of Diagnostics and Public Health, University of Verona, Verona, Italy, ${ }^{2}$ Forensic Toxicology Laboratory, \\ Department of Diagnostics and Public Health, University of Verona, Verona, Italy, ${ }^{3}$ Department of Internal Medicine, Addiction \\ Unit, Verona University Hospital, Verona, Italy
}

\section{OPEN ACCESS}

Edited by:

Giovanni Martinotti,

University of Studies G. d'Annunzio

Chieti and Pescara, Italy

Reviewed by:

Antonio Mirijello,

Casa Sollievo della Sofferenza

(IRCCS), Italy

Francesco Di Carlo,

University of Studies G. d'Annunzio

Chieti and Pescara, Italy

*Correspondence:

Lorenzo Zamboni

lorenzo.zamboni88@gmail.com

Specialty section: This article was submitted to

Addictive Disorders,

a section of the journal

Frontiers in Psychiatry

Received: 24 December 2020 Accepted: 15 February 2021

Published: 18 March 2021

Citation:

Benini A, Gottardo R, Chiamulera C, Bertoldi A, Zamboni $L$ and Lugoboni F

(2021) Continuous Infusion of

Flumazenil in the Management of Benzodiazepines Detoxification.

Front. Psychiatry 12:646038. doi: 10.3389/fpsyt.2021.646038
An effective approach in the treatment of benzodiazepine (BZD) overdosing and detoxification is flumazenil (FLU). Studies in chronic users who discontinued BZD in a clinical setting suggested that multiple slow bolus infusions of FLU reduce BZD withdrawal symptoms. The aim of this study was to confirm FLU efficacy for reducing BZD withdrawal syndrome by means of continuous elastomeric infusion, correlated to drugs plasma level and patients' compliance.

Methods: Seven-day FLU 1 mg/day subcutaneously injected through an elastomeric pump and BZDs lormetazepam, clonazepam, and lorazepam were assessed by HPLC-MS/MS in serum of patients before and after 4 and 7 days of FLU continuous infusion treatment. Changes in withdrawal severity were assessed by using the BZD Withdrawal Scale (BWS).

Results: Fourteen patients (mean age \pm SD $42.5 \pm 8.0$ years, 5 male and 9 female), admitted to the hospital for high-dose BZD detoxification, were enrolled in the study. Serum FLU concentrations significantly decreased from $0.54 \pm 0.33 \mathrm{ng} / \mathrm{ml}$ (mean \pm SD) after 4 days of treatment to $0.1 \pm 0.2 \mathrm{ng} / \mathrm{ml}$ at the end of infusion. Lormetazepam concentrations were $502.5 \pm 610.0 \mathrm{ng} / \mathrm{ml}$ at hospital admission, $26.2 \pm 26.8 \mathrm{ng} / \mathrm{ml}$ after 4 days, and 0 at the end of treatment. BWS values decreased during FLU treatment temporal period. FLU was well-tolerated by patients.

Conclusions: Elastomeric FLU infusion for BZD detoxification is a feasible administration device to maintain adequate, constant, and tolerated FLU concentrations for reducing BZD withdrawal symptoms.

\section{Keywords: benzodiazepine, flumazenil, withdrawal, high dose, detoxifcation}

\section{INTRODUCTION}

Although benzodiazepines (BZDs) constitute one of the most broadly prescribed drug classes worldwide, the frequent and often inappropriate use is a problem that remains considerably underestimated by practitioners and most regulatory agencies (1). BZD can produce tolerance and dependence; thus, their use is recommended for a limited time (2). Surveys carried out in the 1990s in France, Germany, Italy, and the United Kingdom showed that 3.9\% of hypnotic drug users and $3.2 \%$ of anxiolytic drug users had been taking a dose exceeding the recommended 
one (2-4). In Italy, about $7.5-10 \%$ of adult population are BDZ users, half of these being long-term users (LTU) with a diagnosis of BZD use disorder (5). Another study conducted in Italy showed that $14.0 \%$ of patients visiting general practitioners were taking BZDs, with $4.7 \%$ of the total sample being LTU, using BZDs daily for at least 12 months (6).

BZD tolerance was first reported in 1961 (7), but this phenomenon has been often obscured by the enthusiastic use of these drugs, which were able to replace barbiturates. The low toxicity coupled to a high potential of tolerance can lead to very high-dose misuse (8). From a clinical point of view, the only proposed solution of a gradual reduction of BZD is too simplistic. For long-term users, in general, if properly applied, gradually reducing the dosage works, but it is much less effective for high-dose users $(2,8,9)$. This is worth mentioning because withdrawing from high doses of BZD carries significant risk for the health of the patient $(2,10)$.

It is in this area of HDUs that the use of flumazenil (FLU), used worldwide to treat the overdose of BZD, has been demonstrated as effective $(9,11-13)$. Experimental findings have shown that FLU acts as a BZD partial agonist with a weak intrinsic activity, when administered by slow intravenous infusion. While withdrawal symptoms may be brought on by the use of FLU, BZD-tolerant patients only reported mild symptoms $(14,15)$.

BZDs positively modulate $\gamma$-aminobutyric acid (GABA) through distinct binding sites on $\mathrm{GABA}_{\mathrm{A}}$ receptors, and there is little variation among BZDs in pharmacodynamical factors such as selectivity and efficacy. Consequently, the choice of a particular BZD for clinical use is primarily based on pharmacokinetic features. Only one drug, flumazenil (FLU), is currently approved to reverse the effects of BZDs. FLU is a BZD partial agonist commonly used in the treatment of BZD overdose. Studies in chronic users who have discontinued BZDs suggested that multiple slow bolus infusions of FLU reduce the symptoms of BZD withdrawal when compared to placebo (9). The mechanism of FLU action remains, however, unclear: its action may facilitate the coupling of $\mathrm{GABA}_{\mathrm{A}}$ and $\mathrm{BZD}$ receptor complexes, presumably by reversing the down-regulation/uncoupling that occurs with long-term BZD use (16). This mechanism is supposed to underlie FLU's weak agonist action and may explain its ability to attenuate BZD withdrawal symptoms (9). FLU does not antagonize the effects of other CNS sedative-hypnotics, such as ethanol, opioids, or general anesthetics (17).

FLU owns a rapid and extensive distribution phase with high volume of distribution and a second phase with fast metabolic elimination and short half-life (18). Its brief BZD-antagonism duration is due to a rapid hepatic elimination, determining its short half-life (60-90 min) and high plasma clearance (31-78 $1 / \mathrm{h}$ ). The low plasma protein binding of FLU (about 50\%) does not limit its wide distribution (apparent distribution volume $0.6-1.6 \mathrm{l} / \mathrm{kg}$ ) or its partly flow-dependent hepatic elimination $(19,20)$. Pharmacokinetic parameters of FLU do not change whether the drug is administered alone or in combination with other BZDs (18). For BZD detoxification, a viable method is the intravenous administration of FLU by using multiple bolus infusions either alone $(14,21)$ or in combination with tapering doses of BZDs (11).
The pharmacodynamical mechanisms of FLU are therefore crucial to determine its clinical effect, which could be achieved thanks to specific FLU infusion parameters in order to guarantee timing and extent of receptor occupancy (14). Thus, the choice of the most appropriate mode of delivery must be based on the correlation between FLU infusion parameters, plasma levels, and clinical endpoint. Our addiction unit has been employing FLU for high-dose BZD detoxifications since 2003, initially by means of endovenous continuous infusion administered by day. Such mode of delivery was both inconstant at maintaining adequate serum levels, being unfeasible for the night, and uncomfortable for the patient. In order to maintain constant serum concentration of FLU and to reduce modality of administration from multiple to single, we aimed to deliver FLU by slow subcutaneous infusion by using an elastomeric infusion pump at constant flow. In this study, we correlated the efficacy of continuous elastomeric FLU infusion on BZD withdrawal clinical endpoint to both drugs' (FLU and BZDs) plasma levels and, of equal importance, to patients' compliance and tolerance to treatment.

\section{MATERIALS AND METHODS}

This study was approved by the Ethical Review Board of the University Hospital (protocol number: 50771; prog. n. 683CESC). Informed consent was obtained from each subject.

\section{Subjects}

Five male and nine female patients (mean age \pm SD $42.5 \pm$ 8.0 years), admitted to the hospital for BZD detoxification, were enrolled in the study (see Table 1 for patients' characteristics). The BZD use was stopped on day 1 of admission. The therapy with antidepressants, if any (Table 1), was maintained and continued after discharge.

All patients reported a history of BZD dependence according to the Diagnostic and Statistical Manual of Mental Disorders, Fifth Edition (DSM-5) criteria (22). Before hospitalization, all patients were interviewed by a physician to assess degree of BZD dependence and general health conditions. All patients had voluntarily contacted the Addiction Unit of Verona University Hospital and were aware of their BZD dependence.

Inclusion criteria were as follows: (i) age older than 18 years; (ii) diagnosis of BZD use disorder according to the DSM-5 criteria; (iii) BZD abuse lasting more than 6 months; and (iv) high dose of BZD abuse, meaning BZD intake exceeding at least five times the recommended daily amount (e.g., $>50 \mathrm{mg}$ in diazepam equivalents). Individuals were excluded if presenting the following: (i) current substance use disorder, defined as a history of illicit drug dependence or abuse within the previous 6 months; (ii) active medical illnesses or psychosis; and (iii) previous history of seizures, but not due to BZD withdrawal.

\section{Elastomeric Pump}

Patients were treated with a solution containing $7 \mathrm{mg}$ of flumazenil (Anexate ${ }^{\circledR}$, Roche), available commercially in 0.5 $\mathrm{mg} / 5 \mathrm{ml}$ vials at $\mathrm{pH}=4$. The elastomeric pump (Infusor LV 1.5, code $2 \mathrm{C} 1087 \mathrm{~K}$, Baxter S.p.A., Rome, Italy) was arranged with a 
TABLE 1 | Patients' characteristics.

\begin{tabular}{|c|c|c|c|c|}
\hline $\begin{array}{l}\text { Patient } \\
\text { number }\end{array}$ & $\begin{array}{l}\text { Gender } \\
\text { (M/F) }\end{array}$ & $\begin{array}{l}\text { Age } \\
\text { (years) }\end{array}$ & $\begin{array}{l}\text { Reported BDZ dosage } \\
\text { at admission }\end{array}$ & $\begin{array}{l}\text { Antide } \\
\text { pressant }\end{array}$ \\
\hline 1 & M & 38 & $\begin{array}{l}\text { LRZ } 25 \text { mg/day } \\
\text { CLO } 2 \text { mg/day }\end{array}$ & Agomelatine \\
\hline 2 & M & 44 & LRM 75 mg/day & None \\
\hline 3 & $\mathrm{~F}$ & 42 & LRM 75 mg/day & Duloxetine \\
\hline 4 & $\mathrm{~F}$ & 55 & ALP 35 mg/day & Escitalopram \\
\hline 5 & $\mathrm{~F}$ & 47 & CLO 12 mg/day & Mirtazapine \\
\hline 6 & $\mathrm{~F}$ & 52 & $\begin{array}{l}\text { LRM } 25 \text { mg/day } \\
\text { LRM } 12 \text { mg/day } \\
\text { DZP } 100 \text { mg/day } \\
\text { DZP } 30 \text { mg/day } \\
\text { FLZ } 180 \text { mg/day } \\
\text { TRZ } 1.5 \text { mg/day } \\
\text { LRZ } 15 \text { mg/day } \\
\text { ALP } 4 \text { mg/day } \\
\text { CLO } 12 \text { mg/day }\end{array}$ & $\begin{array}{l}\text { Venlafaxine } \\
\text { plus } \\
\text { agomelatine }\end{array}$ \\
\hline 7 & $\mathrm{~F}$ & 47 & $\begin{array}{l}\text { LRM } 400 \text { mg/day } \\
\text { DLZ } 12 \text { mg/day }\end{array}$ & Agomelatine \\
\hline 8 & $\mathrm{~F}$ & 37 & LRM 40 mg/day & Agomelatine \\
\hline 9 & M & 36 & LRM 150 mg/day & None \\
\hline 10 & $\mathrm{~F}$ & 43 & LRZ 50 mg/day & Citalopram \\
\hline 11 & $\mathrm{~F}$ & 31 & LRM 100 mg/day & Paroxetine \\
\hline 12 & $\mathrm{~F}$ & 30 & LRM 75 mg/day & Sertraline \\
\hline 13 & M & 38 & ALP 15 mg/day & Escitalopram \\
\hline 14 & M & 32 & LRM 150 mg/day & Citalopram \\
\hline
\end{tabular}

ALP, aprazolam; CLO, clonazepam; DLZ, delorazepam; DZP, diazepam; F, female; FLZ, flurazepam; $L R M$, lormetazepam; $L R Z$, lorazepam; $M$, male; $T R Z$, triazolam.

maximum capacity of $250 \mathrm{ml}$ and constant release of $1.5 \mathrm{ml} / \mathrm{h}$ for 7 days. The pump was connected to the patient's anterior abdominal wall via a butterfly needle inserted subcutaneously. The pump, releasing $1 \mathrm{mg}$ of flumazenil every $24 \mathrm{~h}$, was then placed in a small bag that could be carried attached to the belt or on the shoulder. Patients' tolerance for the infusion device was investigated on a daily basis, through clinical examination and interview.

Throughout the detoxification, FLU subcutaneous infusion (FLU-SI) was associated with therapeutic doses of clonazepam, orally administered every day in the evening and gradually tapered from $6 \mathrm{mg}$ on the 1st day to $0.5-2.0 \mathrm{mg}$ on the last day of treatment. The different speed in the tapering of clonazepam was due to clinical criteria, in particular we considered the quality of sleep and the intensity of withdrawal symptoms. In this way, at the end of hospitalization, $3 / 14$ patients were discharged with no clonazepam, and 11/14 (78.6\%) patients were discharged with a low dose of clonazepam ranging from 0.5 to $2.0 \mathrm{mg} /$ day; these patients were recommended to gradually taper it in a few weeks (8). Unfortunately, patients were not followed-up as outpatients, and we cannot be sure whether they succeeded in tapering and eventually stopping clonazepam.

Ten days prior to the admission, anti-epileptic prophylaxis (1 $\mathrm{g}$ /day valproic acid or levetiracetam) was given to all patients in order to prevent seizures during treatment. Anti-epileptic treatment was maintained during the hospital stay and for further 20-40 days after discharge.

Patients under concurrent treatment with antidepressant (12/14 patients, see Table 1) were maintained under this pharmacotherapy.

\section{Sampling Protocol}

Blood samples were collected without anticoagulant at the moment of admission, after 4 days of FLU treatment, and at the end of the 7 days of treatment, before discharge from the addiction unit.

Samples were centrifuged (3,000 rpm, $10 \mathrm{~min})$ and sera were frozen at $-80^{\circ} \mathrm{C}$ until HPLC-MS analysis.

\section{Flumazenil and Main BZD Concentration Analysis}

Blank serum samples, used for the development and validation of the procedure, were obtained from healthy volunteers abstinent from any drug during the week before sampling. A 250- $\mu$ l aliquot of serum was added to an equal volume of $0.1 \mathrm{M}$ phosphate solution ( $\mathrm{pH} 8.8$ ), and the mixture was spiked with the IS (diazepam-D5) to have a final concentration of $40 \mathrm{ng} / \mathrm{ml}$. The mixtures were added with $1.5 \mathrm{ml}$ of ethyl acetate, then extracted by vortex-mixing for $1 \mathrm{~min}$, and centrifuged at 4,000 rpm for $15 \mathrm{~min}$. The organic phase was then evaporated to dryness under nitrogen stream and the residue dissolved in $50 \mu \mathrm{l}$ of ultrapure water.

The determination of FLU and lormetazepam was obtained by using a model 1290 UHPLC coupled to a model 6450 triple quadruple mass spectrometer (Agilent Technologies, Waldbronn, Germany) operating in positive ionization mode. Gradient elution was performed on a UHPLC ZORBAX Eclipse reversed-phase column (RRHD $2.1 \mathrm{~mm} \times 100 \mathrm{~mm}$, $1.8 \mu \mathrm{m}$ ) (Agilent) by mixing $5 \mathrm{mM}$ aqueous ammonium formate containing $0.01 \%$ formic acid (eluent $\mathrm{A}$ ) and acetonitrile added with $0.01 \%$ formic acid at a flow rate of $0.5 \mathrm{ml} / \mathrm{min}$ (eluent B) from 10 to $95 \% \mathrm{~B}$ in $7 \mathrm{~min}$. The analyses were performed in multiple reaction ion monitoring (MRM) mode using the following ion transitions: FLU 304 217, 232, and 258 (collision energy: $20 \mathrm{eV}$ ); lormetazepam 335 317, 289, and 177.0 (collision energy: $20 \mathrm{eV}$ ); and diazepam-D5 290262 (collision energy: $27 \mathrm{eV})$.

Method was linear in the concentration range of $78-5,000$ $\mathrm{pg} / \mathrm{ml}$ for FLU and of 3-200 $\mathrm{ng} / \mathrm{ml}$ for lormetazepam. Lower limit of quantification (LLOQ) corresponded to $78 \mathrm{pg} / \mathrm{ml}$ for FLU and $3 \mathrm{ng} / \mathrm{ml}$ for lormetazepam.

Precision (\% CV) of the assay was $\leq 9.8 \%$ for both the analytes, whereas the inter-assay accuracy was $\leq 3.8$ and $\leq 4.7 \%$, respectively. The accuracy and CVs for day-to-day tests resulted always below $7.93 \%$.

\section{Withdrawal Assessment}

A Benzodiazepine Withdrawal Scale (BWS) form exploring withdrawal symptoms (33 items each with a score of 0-4 from best to worst) was given to each patient for daily report (23). 


\section{Statistical Analysis}

Statistical analysis was performed using the software Graph Pad PRISM version 6.0. The results were expressed as mean \pm standard error of the mean (SEM). Student's $t$-test was utilized for statistical analysis by comparing different treatment times of the same group of patients.

\section{RESULTS}

Drug plasma levels are shown in Figure 1. Plasma FLU concentrations were $0.54 \pm 0.089 \mathrm{ng} / \mathrm{ml}$ (mean $\pm \mathrm{SEM}$ ) at $\mathrm{T} 1$ after 4 days of continuous subcutaneous infusion, ranging from 0.14 to $1.4 \mathrm{ng} / \mathrm{ml}$. Values recorded at T2 (end of therapy) were $0.09 \pm 0.05 \mathrm{ng} / \mathrm{ml}$, with FLU concentrations below limits of detection in 10 patients out of 14 .

Lormetazepam (LRM) levels were $502.5 \pm 163.0 \mathrm{ng} / \mathrm{ml}$ at T0 baseline. A significant decrease $(11.2 \pm 5.7 \mathrm{ng} / \mathrm{ml} ; p=0.008)$ in LRM levels was recorded at T1 and $0.43 \pm 0.43 \mathrm{ng} / \mathrm{ml}$ at T2. High LRM plasma levels recorded at T0 are in agreement with patients' self-report of BZD use at admission, whereas low T1 and T2 levels confirmed compliance to detoxification treatment.

Lorazepam (LRZ) levels showed a similar pattern, with high initial plasma concentrations $(83.1 \pm 27.4 \mathrm{ng} / \mathrm{ml})$, then a significant decrease to $20.4 \pm 11.4 \mathrm{ng} / \mathrm{ml}(p=0.01)$ at $\mathrm{T} 1$ and $9.4 \pm 5.6 \mathrm{ng} / \mathrm{ml}$ at T2 after 7 days of FLU administration.

Clonazepam (CLN) plasma levels were low at T0 (14.0 \pm $8.6 \mathrm{ng} / \mathrm{ml}), 35.5 \pm 5.0 \mathrm{ng} / \mathrm{ml}$ at T1, and $25.4 \pm 3.9 \mathrm{ng} / \mathrm{ml}$ at T2. Note that three patients were treated with CLN before hospital admission (see Table $\mathbf{1}$ ).

According to different BZD behaviors, BWS showed a decrease from 26.4 to 17.7 points, as portrayed in Figure 2. During the treatment, 10/14 subjects (71.4\%) completed the Benzodiazepine Withdrawal Scale (BWS) with scores ranging from 0 to 132 on a daily basis, in order to subjectively assess their withdrawal symptoms. Four out of 14 patients could not complete the BWS. As shown in Figure 2, BWS improved significantly during FLU treatment in all subjects. No major event (i.e., convulsive crisis) occurred.

The elastomeric pump was well tolerated by patients. Since FLU is further diluted in a saline solution inside the device, no skin irritation around the insertion of the needle was noticed. Since elastomeric pumps are light and compact, patients appreciated the freedom of movement and rated them as painless, safe, and comfortable, with no bound to the pump and respecting the privacy about the therapy, whereas nurses acknowledged they required less time to manage them.

\section{DISCUSSION}

BZD represents a class of drugs characterized by low acute toxicity even at high doses in the absence of any concurrent drug abuse such as alcohol and opioids (2). Literature data on the toxicity of high-dose BZD are old and mostly based on anecdotal case reports. The lack of clinical studies and the high tolerability of these drugs have produced the erroneous perception that the administration of high doses of BZD for a prolonged time, although not recommended, could be not harmful. However, several complications have been associated to chronic BZD consumption, such as memory and attention deficit, inability to learn, increased risk of falls, road accidents, depression, and reduced quality of life (Lugoboni DAD 2014). Thus, although the prolonged use of high dose of BZD seems not to induce liver toxicity, it remains a serious health concern (24). The severe discomfort experienced by patients stopping longterm BZD use led to the development of treatment strategies for discontinuing these medications $(1,10)$. The common management of BZD withdrawal syndrome includes, either individually or in combination: (i) a gradual tapering of the drug; (ii) switching to an equivalent dose of a long half-life BZD before tapering withdrawal $(10,25)$; and (iii) adding medications prior to detoxification and continuing those medications after BZD discontinuation $(1,10)$. A potential approach is the abrupt discontinuation of the medication and a rapid BZD detoxification using FLU. FLU is commonly used in the treatment of BZD overdose; it is usually considered a BZD antagonist (9). When compared to placebo, bolus infusion of flumazenil (1 mg in $5 \mathrm{~min}$ ) produced effects similar to BZD withdrawal in BZD users $(23,26)$. Nonetheless, results of studies in chronic BZD users who have discontinued BZD use suggest that multiple slow bolus infusions of flumazenil reduce the symptoms of withdrawal $(9,11,21,27)$.

Subcutaneous route of FLU administration was previously described only in three patients (14), suggesting the usefulness of this route for its excellent tolerability, efficacy, and improvement on measure of psychological distress. According to these data, we decided to administer FLU by subcutaneous route utilizing elastomeric pumps normally used for pain control in cancer patients or, more recently, for continuous infusion of antibiotics (28) or for treatment of idiopathic hypersomnia (29).

To our knowledge, the results present in this paper are the first data of FLU serum concentrations following subcutaneous infusion by elastomeric pump described in literature. FLU serum concentrations were low, but consistent with data of FLU administered by i.v. route (14).

FLU is characterized by short half-life $(0.8-1.2 \mathrm{~h})$ (30) and requires repeated doses or continuous infusion to reverse BZD overdose. In spite of its low lipophilicity, FLU has a large volume of distribution, and its weak binding to plasma proteins explains its rapid distribution. Moreover, FLU is extensively metabolized by hepatic cytochromes $\mathrm{P} 450$ 3A4, 3A5, and 2C9 and readily eliminated. Maximum brain concentrations are reached 5 to 8 min after i.v. administration (31).

Subcutaneous administration of flumazenil eliminates some problems with first-pass hepatic metabolism observed orally and is likely to facilitate better absorption. Subcutaneous administration also provides continuous dosing, which would be hard to achieve with oral or sublingual administration, and the slow absorption may abrogate side effects related to high serum concentrations. The subcutaneous route is easier to establish than the intravenous administration, and there is no risk for patient's veins. Study data suggested that flumazenil administered by the s.c. route might have equitable clinical benefits to i.v. administration, but it might be superior in that it requires less 

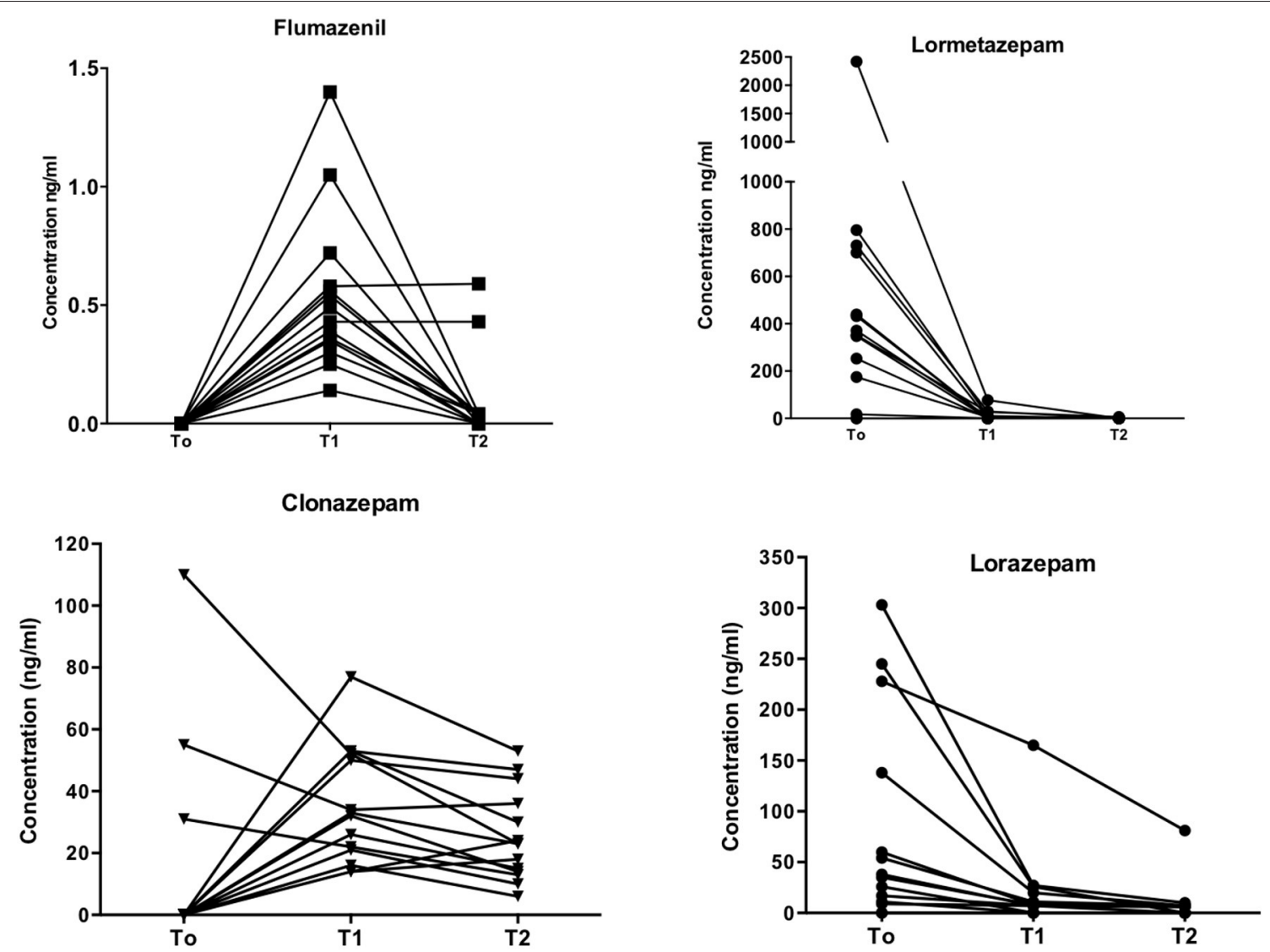

FIGURE 1 | Drugs plasma levels. Individual plasma levels ( $\mathrm{ng} / \mathrm{ml}$; ordinates) for flumazenil, lormetazepam, clonazepam, and lorazepam at different time-points (abscissa), i.e., at admission (TO), four (T1) and seven days after flumazenil start of elastomeric infusion.

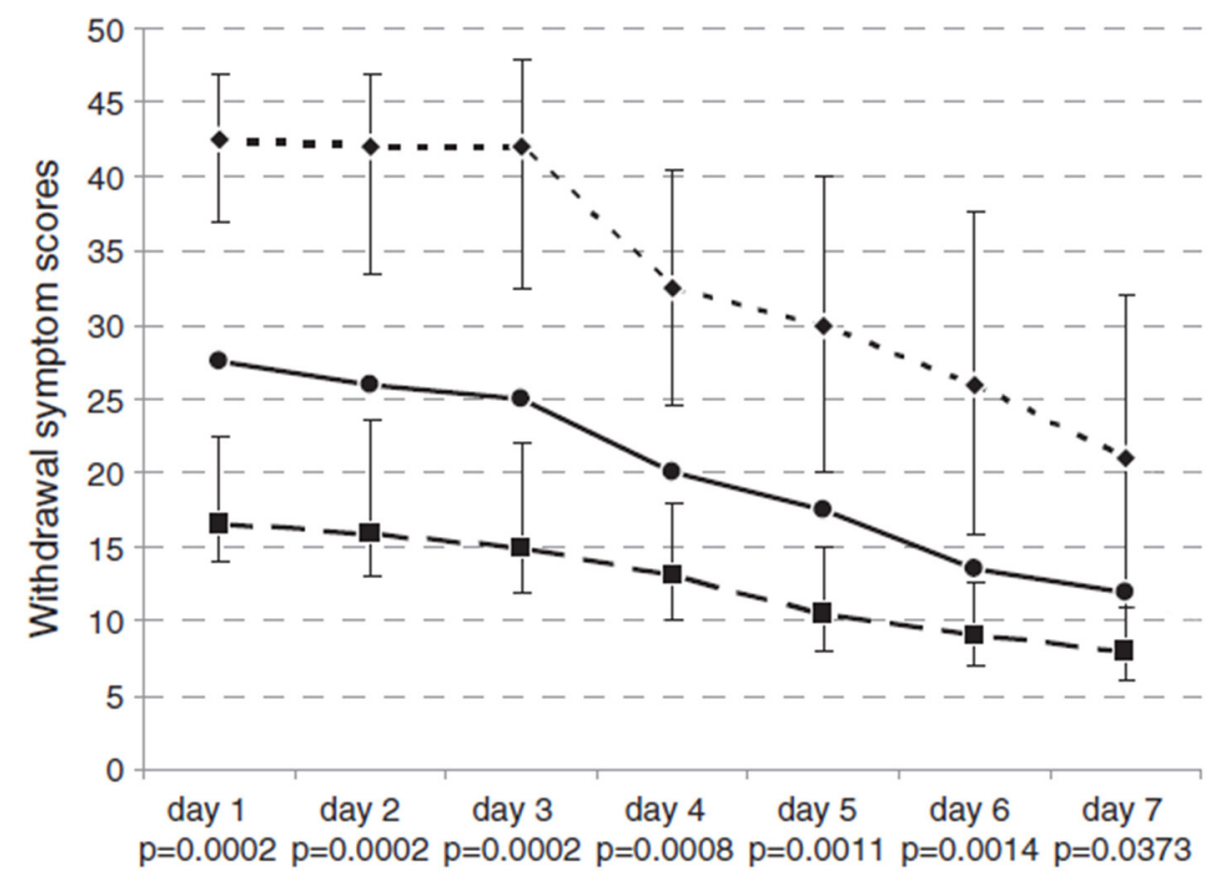

FIGURE 2 | Withdrawal Symptom Scores from day 1 to day 7 of FLU-SI treatment. 
clinical monitoring and is likely associated with less equipment problems (i.e., dislodged or blocked i.v. needle/line) and adverse events (i.e., venous tissue irritation). These advantages, as well as an improved patient mobility over the treatment period, will also likely result in increased patient satisfaction $(9,14)$.

The subcutaneous route of administration may be associated to the absence of adverse events associated with i.v. FLU administration. In fact, our patients did not report any kind of adverse events such as those frequently reported during or after FLU administration $(8,14,32)$.

Our results demonstrated low and constant serum concentrations during all treatment and a prompt decrease nearly to 0 at the end of treatment, protecting patients from peak serum levels. We utilized an elastomeric infusion pump mostly utilized in our hospital for analgesic purposes.

Several elastomeric pumps are commercially available, and they are calibrated in different conditions, including operating temperature and pressure, viscosity of fluid, backpressure, and time recommended between filling of the device and beginning of the infusion. All of these factors affect the infusion rate of pumps. Elastomeric infusion pumps are feasible to use and less bed bounding for patients, although a little less precise than other pumps.

Moreover, Höjer et al. (33) studied the stability of infusion solutions of flumazenil in concentrations of 1.0 and $5.0 \mu \mathrm{g} / \mathrm{ml}$ stored for periods of up to 9 months and concluded that the stability of flumazenil in infusion solution was satisfactory.

Importantly, serum levels of other BZDs (such as LRM and LRZ) are 0 after 4 days of FLU administration, proving both the efficacy of FLU and patients' compliance despite the elevated BZD plasma levels measured at the beginning of the treatment. The good patients' compliance was confirmed by CLN concentrations in serum that showed a trend to decrease after 7 days. Most interestingly, during the detoxification process, all patients reported low levels of craving for $\mathrm{BZD}$, which might represent a rarely seen feature in the spectrum of drug detoxification. According to previous studies, high-dose BZD chronic use determines a severe impairment of psychological, physical, and social functioning, along with a significant reduction of quality of life $(34,35)$.

\section{REFERENCES}

1. Soyka M. Treatment of benzodiazepine dependence. N Engl J Med. (2017) 376:2399-400. doi: 10.1056/NEJMc1705239

2. Lader M. Benzodiazepines revisited: will we ever learn? Addiction. (2011) 106:2086-2109. doi: 10.1111/j.1360-0443.2011.03563.x

3. Petitjean S, Ladewig D, Meier CR, Amrein, R, Wiesbeck GA. Benzodiazepine prescribing to the Swiss adult population: results from a national survey of community pharmacies. Int Clin Psychopharmacol. (2007) 22:292-8. doi: 10.1097/YIC.0b013e328105e0f2

4. Ohayon MM, Lader MH. Use of psychotropic medication in the general population of France, Germany, Italy, and the United Kingdom. J Clin Psychiatry. (2002) 63:817-25. doi: 10.4088/JCP.v63n0912

5. Magrini N, Vaccheri A, Parma E, D’Alessandro R, Bottoni A, Occhionero M, et al. Use of benzodiazepines in the Italian general population. Prevalence, patterns of use and risk factors for use. Eur J Clin Pharmacol. (1996) 50:19-25. doi: $10.1007 /$ s002280050063
The main limitation to this study is the lack of a follow-up phase to determine whether all patients were successfully able to taper and suspend clonazepam and to assess the relapse rate. Another limitation of the study is its monocentric design. The problem is not new. Although more than 30 years have passed since the first studies of the efficacy of FLU in the treatment of addiction to high doses of BZD, to our knowledge, there are no more than five centers worldwide offering this treatment. This continues to represent a major obstacle to the definition of more shared and standardized protocols. Currently, FLU protocol is the same for all patients, regardless of sex, age, BMI, and BZD daily intake. Future prospects should include further investigations of the individual variables and clinical outcomes in order to individualize the detoxification therapy.

\section{DATA AVAILABILITY STATEMENT}

The raw data supporting the conclusions of this article will be made available by the authors, without undue reservation.

\section{ETHICS STATEMENT}

The studies involving human participants were reviewed and approved by CE 292CESC. The patients/participants provided their written informed consent to participate in this study.

\section{AUTHOR CONTRIBUTIONS}

ABen and RG equally contributed for the analytes'plasma measurements. ABen, $\mathrm{CC}$, and ABer contributed to the manuscript's draft and proofreading. LZ processed the statistical analysis and FL followed the clinical part and designed the study. All authors contributed to the article and approved the submitted version.

\section{ACKNOWLEDGMENTS}

The authors would like to remember the figure of Malcolm Lader (1936-2020), our mentor in pharmacological research on benzodiazepines and their misuse.

6. Barbui C, Gregis M, Zappa M. A cross-sectional audit of benzodiazepine use among general practice patients. Acta Psychiatr Scand. (1998) 97:153-6. doi: 10.1111/j.1600-0447.1998.tb09979.x

7. Hollister LE, Motzenbecker FP, Degan RO. Withdrawal reactions from chlordiazepoxide ("Librium"). Psychopharmacologia. (1961) 2:63-8. doi: 10.1007/BF00429621

8. Faccini M, Leone R, Opri S, Casari R, Resentera C, Morbioli L, et al. Slow subcutaneous infusion of flumazenil for the treatment of long-term, highdose benzodiazepine users: a review of 214 cases. J Psychopharmacol. (2016) 30:1047-53. doi: 10.1177/0269881116647505

9. Hood SD, Norman A, Hince DA, Melichar JK, Hulse GK. Benzodiazepine dependence and its treatment with low dose flumazenil. Br J Clin Pharmacol. (2014) 77:285-94. doi: 10.1111/bcp.12023

10. Denis C, Fatséas M, Lavie E, Auriacombe M. Pharmacological interventions for benzodiazepine mono-dependence management in outpatient settings. Cochrane Database Syst Rev. (2006) (3):CD005194. doi: 10.1002/14651858.CD005194.pub2 
11. Gerra G, Zaimovic A, Giusti F, Moi G, Brewer C. Intravenous flumazenil versus oxazepam tapering in the treatment of benzodiazepine withdrawal: a randomized, placebo-controlled study. Addict Biol. (2002) 7:385-95. doi: 10.1080/1355621021000005973

12. Faccini M, Tamburin S, Casari R, Morbioli L, Lugoboni F. High-dose lormetazepam dependence: strange case of Dr. Jekyll and Mr Hyde. Intern Emerg Med. (2019) 14:1271-8. doi: 10.1007/s11739-019-02101-8

13. Gallo AT, Hulse G. Pharmacological uses of flumazenil in benzodiazepine use disorders: a systematic review of limited data. J Psychopharmacol. (2021) 9:269881120981390. doi: 10.1177/0269881120981390

14. Hulse GK, O’Neil G, Morris N, Bennett K, Norman A, Hood SD. Withdrawal and psychological sequelae, and patient satisfaction associated with subcutaneous flumazenil infusion for the management of benzodiazepine withdrawal: a case series. J Psychopharmacol. (2013) 27:222-7. doi: 10.1177/0269881112446532

15. Tamburin S, Mantovani E, Bertoldi A, Federico A, Casari R, Lugoboni F. High-dose dependence and cognitive side effects to medical prescription of etizolam. Front Psychiatry. (2020) 11:601827. doi: 10.3389/fpsyt.2020.601827

16. Pericić D, Jazvinsćak Jembrek M, Svob Strac D, Lazić J, Spoljarić IR. Enhancement of benzodiazepine binding sites following chronic treatment with flumazenil. Eur J Pharmacol. (2005) 507:7-13. doi: 10.1016/j.ejphar.2004.10.057

17. Mascia MP, Ledda G, Orrù A, Marongiu A, Loriga G, Maciocco E, et al. Differential modulation of GABA(A) receptor function by aryl pyrazoles. Eur J Pharmacol. (2014) 15:1-6. doi: 10.1016/j.ejphar.2014.03.039

18. Weinbroum AA, Flaishon R, Sorkine P, Szold O, Rudick V. A risk-benefit assessment of flumazenil in the management of benzodiazepine overdose. Drug Saf. (1997) 17:181-96. doi: 10.2165/00002018-199717030-00004

19. Whithwam JG, Amrein R. Pharmacology of flumazenil. Acta Anaesthesiol Scand. (1995) 59 (Suppl. 108):3-14. doi: 10.1111/j.1399-6576.1995.tb04374.x

20. Klotz U, Kanto J. Pharmacokinetics and Clinical Use of Flumazenil (Ro 15-1788). Clin Pharmacokinet. (1988) 14:1-12. doi: 10.2165/00003088-198814010-00001

21. Saxon L, Hjemdahl P, Hiltunen AJ, Borg S. Effects of flumazenil in the treatment of benzodiazepine withdrawal-a double-blind pilot study. Psychopharmacology (Berl). (1997). 131:153-60. doi: 10.1007/s002130050278

22. American Psychiatric Association. American Psychiatric Association Diagnostic and Statistical Manual of Mental Disorders DSM-5, 5th edn. Washington, DC: American Psychiatric Publishing (2013).

23. Mintzer MZ, Stoller KB, Griffiths RR. A controlled study of flumazenilprecipitated withdrawal in chronic low-dose benzodiazepine users. Psychopharmacology (Berl). (1999) 147:200-9. doi: 10.1007/s0021300 51161

24. Lugoboni F, Mirijello A, Morbioli L, Arzenton E, Leone R, Faccini M, et al. Does high-dose benzodiazepine abuse really produce liver toxicity? Results from a series of 201 benzodiazepine monoabusers. Expert Opin Drug Saf. (2018) 17:451-456. doi: 10.1080/14740338.2018.1457646
25. Lader M, Tylee A, Donoghue J. Withdrawing benzodiazepines in primary care. CNS Drugs. (2009) 23:19-34. doi: 10.2165/0023210-200923010-00002

26. Mintzer MZ, Griffiths RR. Flumazenil-precipitated withdrawal in healthy volunteers following repeated diazepam exposure. Psychopharmacology. (2005) 178:259-67. doi: 10.1007/s00213-004-2009-1

27. Federico A, Lugoboni F, Mantovani E, Martini A, Morbioli L, Casari $\mathrm{R}$, et al. Detoxification Improves Multidomain Cognitive Dysfunction in High-Dose Benzodiazepine Abusers. Front Neurosci. (2020) 14:747. doi: $10.3389 /$ fnins. 2020.00747

28. Mujal A, Sola J, Hernandez M, Villarino MA, Baylina M, Tajan J, et al. Safety and effectiveness of outpatient parenteral antimicrobial therapy in older people. J Antimicrob Chemother. (2016) 71:1402-1407. doi: $10.1093 / \mathrm{jac} / \mathrm{dkv} 478$

29. Kelty E, Martyn V, O’Neil G, Hulse GK. Use of subcutaneous flumazenil preparations for the treatment of idiopathic hypersomnia: a case report. $J$ Psychopharmacol. (2014) 28:703-6. doi: 10.1177/0269881114523865

30. Bentue-Ferrer D, Bureau M, Patat A, Allain H. Flumazenil. CNS Drug Rev. (1996) 2:390-414. doi: 10.1111/j.1527-3458.1996.tb00308.x

31. Roncari G, Ziegler WH, Guentert TW. Pharmacokinetics of the new benzodiazepine antagonist Ro 15-1788 in man following intravenous and oral administration. Br J Clin Pharmacol. (1986) 22:421-8. doi: 10.1111/j.1365-2125.1986.tb02912.x

32. Penninga EI, Graudal N, Ladekarl MB, Jürgens G. Adverse events associated with flumazenil treatment for the management of suspected benzodiazepine Intoxication - A Systematic Review with Meta-Analyses of Randomised Trials. Basic Clin Pharmacol Toxicol. (2016) 118:37-44. doi: 10.1111/bcpt.12434

33. Höjer J, Baehrendtz S, Forsström A, Lundqvist T, Jansson B. The stability of flumazenil in infusion solution. Acta Pharm Nordica. (1990) 2:101-4.

34. Lugoboni F, Mirijello A, Addolorato G, Faccini M, Casari R, Cossari $A$, et al. Quality of life in a cohort of high-dose benzodiazepine dependent patients. Drug Alcohol Depend. (2014) 142:105-9. doi: 10.1016/j.drugalcdep.2014.06.020

35. Tamburin S, Federico A, Faccini M, Casari R, Morbioli L, Sartore V, et al. Determinants of quality of life in high-dose benzodiazepine misusers. Int J Environ Res Public Health. (2017) 14:38. doi: 10.3390/ijerph14010038

Conflict of Interest: The authors declare that the research was conducted in the absence of any commercial or financial relationships that could be construed as a potential conflict of interest.

Copyright (C) 2021 Benini, Gottardo, Chiamulera, Bertoldi, Zamboni and Lugoboni. This is an open-access article distributed under the terms of the Creative Commons Attribution License (CC BY). The use, distribution or reproduction in other forums is permitted, provided the original author(s) and the copyright owner(s) are credited and that the original publication in this journal is cited, in accordance with accepted academic practice. No use, distribution or reproduction is permitted which does not comply with these terms. 